\title{
Sistema Nacional de Cultura: um estado da arte da produção acadêmica com foco nos estudos de caso de municípios
}

\section{Clarissa Alexandra Guajardo Semensato ${ }^{1}$}

\author{
Alexandre Almeida Barbalho ${ }^{2}$
}

Resumo: $O$ objetivo deste artigo é tecer um estado da arte das monografias realizadas em cursos de pós-graduação stricto sensu que tenham como temáticas o Sistema Nacional de Cultura (SNC) e os Sistemas Municipais de Cultura (SMCs). A proposta é obter um panorama geral sobre a produção teórica envolvida, suas áreas de conhecimento, distribuição territorial; bem como observar as características marcantes da política pública que estes estudos apontam no âmbito municipal. Foi possível perceber que, embora estes estudos tenham sido produzidos em contextos diferentes, com objetivos e hipóteses distintos, além de métodos particulares de suas próprias áreas de conhecimento, seus resultados dialogam, mostrando um grau de conformidade nos efeitos de implementação da política nos municípios.

Palavras-chave: Estado da arte; Sistema Nacional de Cultura; municípios

Sistema Nacional de Cultura: un estado del arte de la producción académica con un enfoque en estudios de casos de municipios

Resumen: El objetivo de este artículo es tejer un estado del arte de las monografías realizadas en cursos de posgrado estricto sensu que tienen como temas el Sistema Nacional de Cultura (SNC) y los Sistemas de Municipales de Cultura (SMC). La propuesta es obtener una visión general de la producción teórica involucrada, sus

\footnotetext{
${ }^{1}$ Clarissa Alexandra Guajardo Semensato. Doutoranda no Programa de Pós Graduação em Políticas Públicas da Universidade Estadual do Ceará, Brasil. Mestre em Políticas Sociais pela Universidade Estadual do Norte Fluminense. E-mail: clarissaalexandra@gmail.com - https://orcid.org/0000-0003-42780757

${ }^{2}$ Alexandre Almeida Barbalho. Doutor em Comunicação e Cultura Contemporâneas pela Universidade Federal da Bahia. Professor dos Programas de Pós-Graduação em Sociologia e em Políticas Públicas da Universidade Estadual do Ceará e em Comunicação da Universidade Federal do Ceará, Brasil. E-mail:alexandrealmeidabarbalho@gmail.com - https://orcid.org/0000-0003-4612-6162
} 
áreas de conocimiento, distribución territorial; además de observar las características principales de la política pública que estos estudios señalan a nivel municipal. Fue posible notar que, aunque estos estudios se produjeron en diferentes contextos, con diferentes objetivos e hipótesis, además de métodos particulares de sus propias áreas de conocimiento, sus resultados son similares, presentando una conformidad en los efectos de la implementación de políticas en los municipios.

Palabras clave: Estado del arte; Sistema Nacional de Cultura; municipios

National System of Culture: a state of art in academic production with focus on municipalities study of cases

Abstract: The objective of this article is to weave the state of the art of the monographs carried out in stricto sensu postgraduate courses that have as themes the National System of Culture (NSC) and the Municipal System of Culture (MSCs). The proposal is to obtain a general overview of the theoretical production involved, its areas of knowledge, territorial distribution; as well as to observe the main characteristics that these studies point out in the public policy at the municipal level. It was possible to notice that, although these studies were produced in different contexts, with different objectives and hypotheses, and using particular methods from their own areas of knowledge, their results are similar, showing analogous effects of policy implementation in the municipalities.

Keywords: State of art; National System of Culture; municipalities

\section{Sistema Nacional de Cultura: um estado da arte da produção acadêmica com foco nos estudos de caso de municípios}

\section{Introdução}

Este artigo tem por objetivo traçar um panorama comparativo sobre a produção acadêmica relacionada ao Sistema Nacional de Cultura (SNC) e aos Sistemas Municipais de Cultura (SMCs), tendo como base de dados 0
Catálogo de Teses e Dissertações da CAPES $^{3}$. A análise comparada dos estudos foi norteada pelas

\footnotetext{
${ }^{3}$ Este levantamento faz parte de uma pesquisa de doutoramento realizada no âmbito do Programa de Pós-Graduação em Políticas Públicas da Universidade Estadual do Ceará, com apoio da Fundação Cearense de Apoio ao Desenvolvimento Científico e Tecnológico no fornecimento de bolsa de pesquisa.
} 
seguintes questões de pesquisa: sendo os estudos em políticas culturais tradicionalmente multidisciplinares ${ }^{4}$, aqueles que têm como objeto a política pública de Sistemas de Cultura, trazem resultados análogos, mesmo com métodos e perspectivas particulares de cada área? E, os resultados dialogam entre si, mesmo que produzidos em contextos (tempo e espaço) diferentes?

As questões norteadoras geraram como resultado duas linhas de comparação: uma entre os estudos que tinham o âmbito nacional em seu objeto; e outra entre os estudos de âmbito municipal. Neste presente artigo, por limitações de espaço, vamos expor apenas as análises de âmbito municipal, deixando as análises sobre o SNC em sua esfera nacional para outra oportunidade.

Estudos do tipo estado da arte são motivados pelo desejo de conhecimento do crescimento e da totalidade das pesquisas qualitativas e quantitativas sobre

\footnotetext{
${ }^{4}$ Santos (2017) demonstra que Política Cultural é um tema crescente no Brasil, congregando pesquisadores de diversos campos do saber.
}

determinado assunto, principalmente das reflexões desenvolvidas em nível de pósgraduação, produção distribuída por inúmeros programas, mas pouco divulgada (FERREIRA, 2002). A importância de análises desse tipo situa-se na compreensão de que os estudos multidisciplinares, com pluralidade de enfoques sobre um tema, só trarão contribuição realmente efetiva quando articulados de forma a integrar estruturalmente seus resultados, ou evidenciar e explicar incoerências e resultados incompatíveis. É um momento de evolução da ciência, através da ordenação do conjunto de informações e resultados até então obtidos, que permite a integração de perspectivas aparentemente autônomas, a identificação de duplicação, lacunas e vieses (FERREIRA, 2002; SOARES; MACIEL, 2000). É nesse âmbito que se encontram as intenções deste artigo, ao observar os estudos de caso de municípios de modo integrado, articulando seus resultados, na tentativa de ofertar um olhar holístico da produção acadêmica sobre os efeitos de uma 
política nacional nas localidades. Além disso, tem também a intenção de despertar olhares de pesquisadores da temática sobre os estudos já existentes disponíveis para consulta, sobre as discussões recorrentes entre eles, e sobre possíveis lacunas teóricas, para que estas venham ser preenchidas.

O texto estrutura-se em três partes para além desta introdução e da conclusão. A primeira tem 0 objetivo de apresentar o SNC, junto com um breve histórico de sua implantação. A segunda parte visa tecer um panorama dos Trabalhos de Conclusão de Curso de mestres e doutores sobre o tema, observando quantitativamente os objetos de estudo, os programas de formação e áreas do conhecimento ao qual estão vinculados. Outros aspectos abordados são o número de defesas ao longo dos anos, sua distribuição regional e o grau de aproximação com a temática de Sistemas de Cultura como política pública.

A partir das análises quantitativas produzidas na segunda parte do texto, inicia-se a terceira parte, na qual são realizadas apreciações mais profundas que abarcam o conteúdo dos TCCs. Foram utilizados critérios de quantificação do estado da arte a fim de estabelecer um recorte apenas dos estudos com alto grau de relação à temática e que tivessem como objeto estudos de caso de âmbito municipal. Foram selecionados $16^{5}$ trabalhos, dos quais foram lidos: resumos, palavras-chaves, introdução, objetivos/hipóteses e questões de pesquisa; e, conclusão ou consideração final; com a intenção de analisar comparativamente os achados dos pesquisadores a respeito das políticas culturais locais sob a influência do SNC, dificuldades de implementação, manutenção e os efeitos em âmbito municipal.

\section{O Sistema Nacional de}

\section{Cultura}

O SNC é um sistema de gestão de políticas públicas de cultura, incluído na Constituição Federal de 1988, com a Emenda

\footnotetext{
${ }^{5} \mathrm{O}$ recorte quantitativo apontou para 18 estudos, porém 2 estavam indisponíveis para acesso, e por isso foram excluídos da análise.
} 
Constitucional 71/2012 (EC 71), no artigo 216-A, descrito da seguinte forma:

O Sistema Nacional de Cultura, organizado em regime de colaboração, de forma descentralizada e participativa, institui um processo de gestão e promoção conjunta de políticas públicas de cultura, democráticas e permanentes, pactuadas entre os entes da Federação e a sociedade, tendo por objetivo promover 0 desenvolvimento humano, social e econômico com pleno exercício dos direitos culturais (BRASIL, 2012).

A concepção inicial desse projeto já estava disposta no programa de governo do Partido dos Trabalhadores, em 2002, no qual se prevê a implantação de um "Sistema Nacional de Política Cultural', através do qual o poder público garantirá a efetivação de políticas públicas de cultura de forma integrada e democrática, em todo o país" (PT, 2002, p. 20). Sua implantação começa a ocorrer a partir de 2003, tendo Gilberto Gil como ministro da cultura no governo petista, quando o programa de campanha entrou na agenda do governo. Alguns dos marcos desse processo são: a realização da I Conferência Nacional de Cultura (CNC) em 2005, o Projeto de Lei
416/2005 (transformado na EC 71/2012), os Fóruns e Seminários Estaduais do Plano Nacional de Cultura (PNC) em 2008, a II CNC em 2010 e a III CNC, em 2013. Todos estes eventos e processos, além de compor a estrutura do SNC, tiveram a função de articular e angariar 0 apoio de gestores públicos e agentes culturais da sociedade civil em municípios e estados.

O elemento normativo garantidor do SNC atualmente existente é o já mencionado artigo 216-A, inserido na Constituição Federal de 1988 (CF/88) em 2012. Entretanto, o artigo demanda uma regulamentação em lei federal, o que ainda não foi realizado. As tentativas de regulamentação foram o PL338/2013 proposto pelo deputado Rubem Santiago (PDTPE), arquivado em janeiro de 2015 e o PL 4271/2016, apresentado pelo deputado João Derly (Rede-RS) também arquivado em janeiro de 2019, com a mudança da legislatura.

Mesmo sem regulamentação, - dispositivo constitucional já estabelece a estrutura do SNC, 
mencionando inclusive que os elementos que o compõem devem também ser instituídos nas demais esferas federativas, sendo eles:

a. órgãos gestores da cultura;

b. conselhos de política cultural;

c. conferências de cultura;

d. comissões intergestores;

e. planos de cultura;

f. sistemas de financiamento à cultura;

g. sistemas de informações e indicadores culturais;

h. programas de formação na área da cultura; e

i. sistemas setoriais de cultura.

Embora ainda não haja regulamentação que estabeleça formalmente as normativas para adesão dos entes federados, ou que detalhe as atribuições $\mathrm{e}$ competências específicas de cada ente federado, o Ministério da Cultura (MinC) e, agora, a Secretaria Especial de Cultura $^{6}$

\footnotetext{
${ }^{6}$ Atualmente o órgão gestor nacional de política de cultura é a Secretaria Especial da Cultura. O Ministério da Cultura foi extinto no início da gestão do presidente Bolsonaro, que o transformou em Secretaria Especial da Cultura, primeiramente vinculada ao Ministério da Cidadania, e a partir de novembro de 2019 , vinculada ao Ministério do Turismo. A
}

orienta os entes federados desde 2003, através de publicações, cursos e oficinas; e desde então, fazendo pactos através dos instrumentos Protocolo de Intenções, inicialmente, e depois, Acordo de Cooperação Federativa. Os estados e municípios que desejam aderir ao SNC devem implantar em sua esfera administrativa um Sistema de Cultura com as estruturas semelhantes, a fim de viabilizar as relações intergovernamentais e com a sociedade civil. Assim, o SNC se apresenta como: "um modelo de gestão e promoção conjunta de políticas públicas de cultura, pactuadas entre os entes da federação e sociedade civil", com a intenção de ser "um novo paradigma de gestão pública da cultura no Brasil, que tem como essência a coordenação e cooperação intergovernamental" (MinC, 2011, p. 43).

Como informa Roberto Peixe, então Secretário de Articulação Institucional, setor responsável pelo

extinção do órgão, criticada pela classe cultural e artística, para muitos, significa o enfraquecimento da política do SNC. 
SNC no então Ministério da Cultura, o modelo de gestão é constituído por uma estrutura dinâmica, que através da institucionalização das políticas culturais, articula instituições e entes federados, visando de um lado

assegurar a continuidade das políticas públicas da cultura como políticas de Estado, com um nível cada vez mais elevado de participação e controle social. E, de outro, viabilizar estruturas organizacionais e recursos financeiros e humanos, em todos os níveis de governo, compatíveis com a importância da cultura para o desenvolvimento do país. (PEIXE, 2011, p. 14)

Desde que foi criado, o SNC recebe um considerável número de adesões por parte dos entes federados, mesmo sem a lei de regulamentação e sem mecanismos de indução mais concretos, como o repasse de fundos. Ao início de 2020 ,todos os estados mais 0 Distrito Federal são adeptos do SNC; e 2667 municípios, ou 47,9\% dos municípios brasileiros, têm 0 acordo de cooperação publicado em Diário Oficial ${ }^{7}$.

Esse quantitativo se deu a despeito das dificuldades de avanço

\footnotetext{
${ }^{7}$ Dados extraídos de http://snc.cultura.gov.br/, acesso em 10/01/2020.
}

do SNC desde sua criação. Apesar de alguns descompassos relatados por Rubim (2015) e Barbalho (2019), dentre outros, de modo geral, ao longo dos governos PT, a política do SNC nunca foi rompida. Porém, é insustentável defender que ela foi instaurada de modo completo e com pleno êxito. Basta constatar que, como já foi dito, ainda não há lei de regulamentação, e que alguns dos elementos que deveriam ser criados em sua composição, como a Comissão Intergestores Tripartite (CIT) e mecanismos permanentes de repasse de fundos, não existem até hoje. Na terceira parte desse artigo, vamos observar os principais aspectos e dificuldades abordados pelos pesquisadores no processo de implantação da política nos municípios.

\section{Análise de Teses e Dissertações}

A denominação "Estado da Arte" tem sido utilizada para pesquisas de caráter bibliográfico que visam mapear e discutir a produção acadêmica sobre determinado assunto. Costumam 
apresentar uma metodologia de caráter inventariante e descritivo da bibliografia produzida academicamente sobre o tema que se busca investigar (FERREIRA, 2002). Em nosso caso, realizamos aqui um panorama dos estudos que trazem o SNC e/ou Sistemas estaduais e municipais de cultura, como objeto de estudo principal, ou tangencial a outro tema principal.

Como fonte, optamos por utilizar o Catálogo de Teses \& Dissertações da CAPES, com 0 corte temporal até a data de 31/10/2019. A opção por este banco foi em razão de capturar a produção acadêmica de mestrado e doutorado, tendo em vista o considerável período dedicado à pesquisa nestes estudos, de 2 a 4 anos em média; em um texto que expõe de forma detalhada ao leitor, metodologias, abordagens e resultados da investigação. Além disso, este banco dispõe de informações adicionais das instituições e programas aos quais se vinculam os trabalhos, o que possibilita complementar 0 panorama deste Estado da Arte.
$\mathrm{Na}$ busca pelos trabalhos, utilizamos como descrito o termo "Sistema Nacional de Cultura" e/ou "Sistema Municipal de Cultura"e/ou "Sistema Estadual de Cultura" sem a aplicação de filtros, ou seja, foram abarcados trabalhos de todas as áreas do conhecimento, dos cursos de Mestrado Acadêmico, Mestrado Profissional e Doutorado.Esse recorte amplo justifica-se quando cultura, ainda que como política pública, é um campo interdisciplinar que envolve variadas áreas do conhecimento (RUBIM, 2007; SANTOS, 2017; VICENTE, 2019). Os dados dos programas de pósgraduação, as palavras-chaves e resumos também foram considerados para elaboração deste Estado da Arte.

Nos parâmetros acima mencionados, a busca retornou 47 trabalhos, sendo 8 de doutorado e 39 de mestrado.Todos os resumos e palavras-chaves foram lidos, acerca de averiguar se os trabalhos realmente contemplam a temática do SNC, Sistema Estadual de Cultura (SEC) ou SMC. Um deles apresentava-se muito distante do 
tema ${ }^{8}$, portanto não foi quantificado nas análises que se seguirão.Outro, embora alocado no Catálogo, não se constitui em uma dissertação ou tese, e sim em um memorial, com relatos do curso, junto a um artigo acadêmico; e por isso também não foi incluído.Portanto, contabilizam 45 trabalhos a análise do presente estado da arte.

Como era de se esperar de uma política iniciada em 2003 e de longo prazo para implementação, constatou-se $o$ aumento quantitativo de estudos com o passar dos anos, sendo o primeiro deles de 2007:

\footnotetext{
${ }^{8}$ A dissertação em questão trata de Conselhos Estaduais de Comunicação Social, sem adentrar, mesmo que minimamente, na questão do SNC.
} 
Gráfico 1: quantidade de estudos publicados por ano

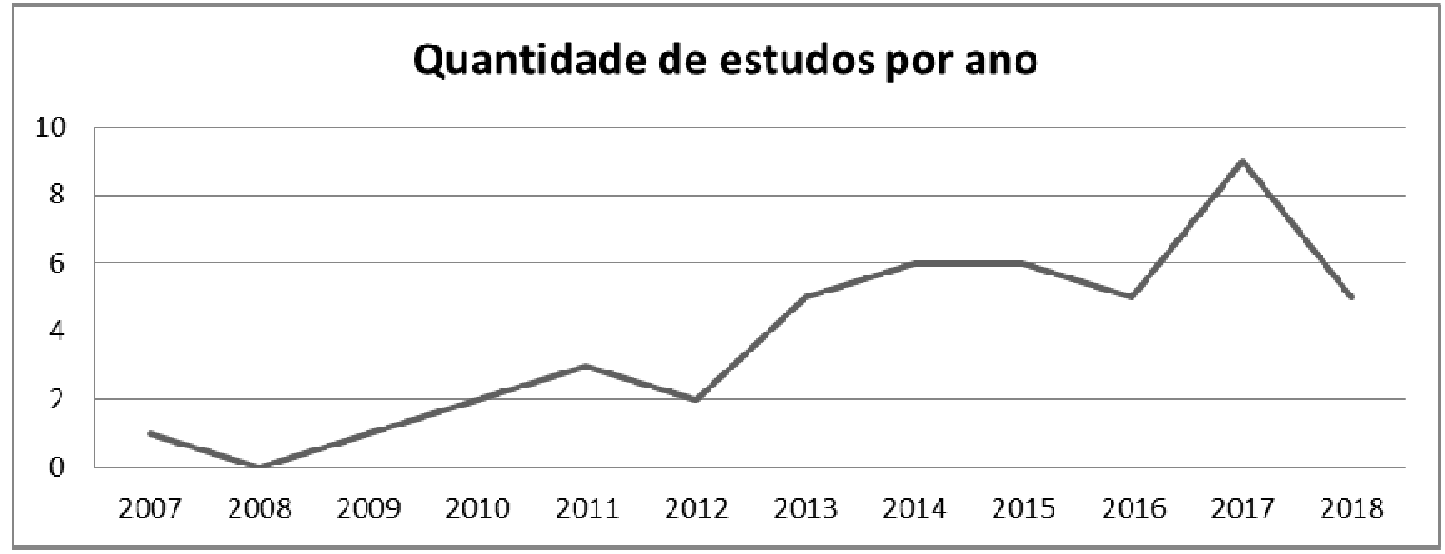

Fonte: Elaboração própria

Também sem surpresa, constatamos a multidisciplinaridade desses estudos, observado as áreas de avaliação dos programas ao qual estão vinculados. Foram encontrados estudos em nove diferentes áreas de avaliação, sendo que a maior parte dos trabalhos enquadram-se nas Interdisciplinar, Sociologia e Administração pública e de empresas, Ciências contábeis e Turismo.

Gráfico 2: programas vinculados aos TCCs por área de avaliação da CAPES

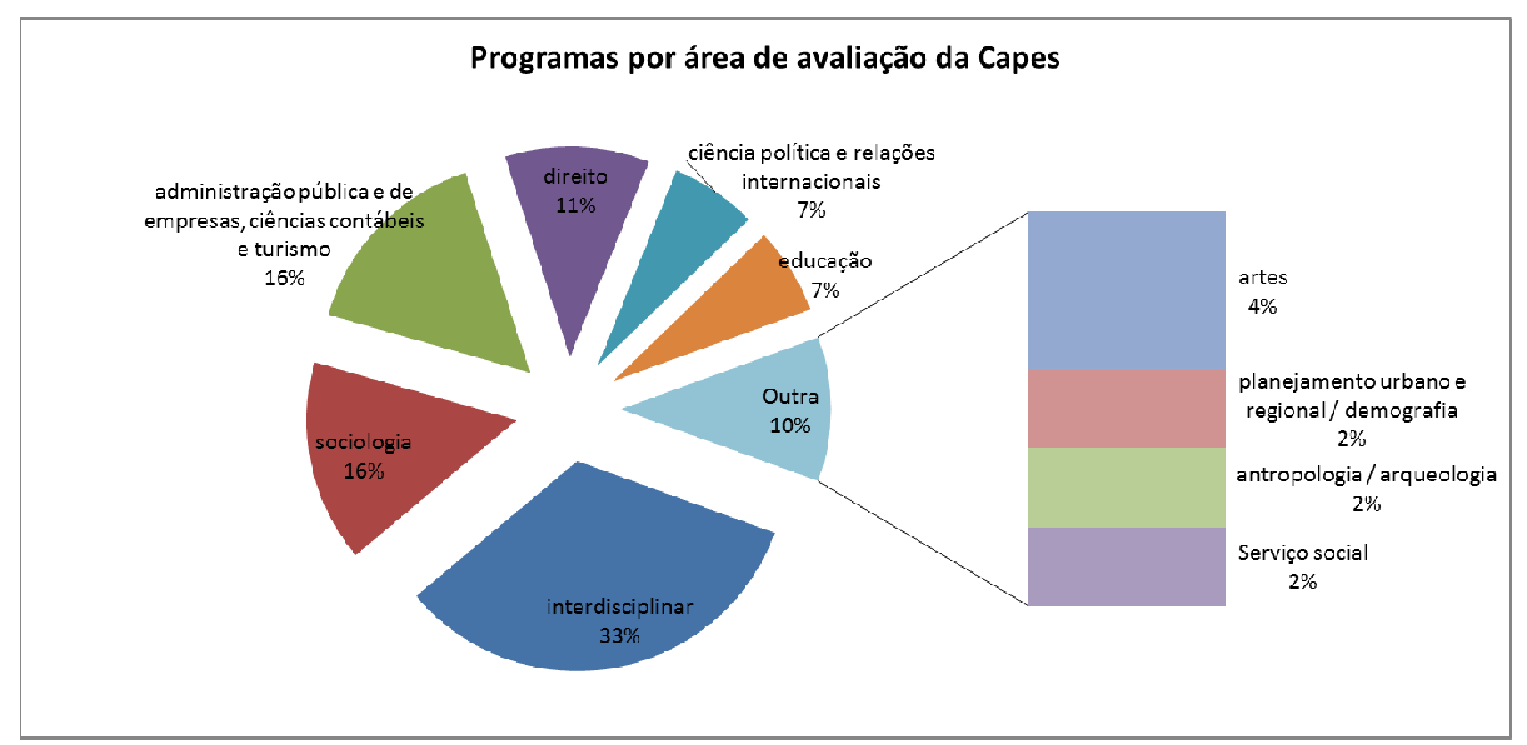

Fonte: Elaboração própria 
Também foi válido observar os aspectos institucionais destes trabalhos. Ao todo, 29 instituições acolheram a temática, sendo a UFBA e a UECE aquelas que mais se destacam, responsáveis por 9 e 4 deles, respectivamente. Essa concentração se justifica principalmente pelo Programa de Pós Graduação Cultura e Sociedade da UFBA, cujo foco é estudos culturais. Somente ele foi responsável por 6 dos estudos.

Obviamente, a existência de programas cujo foco propiciam o acolhimento da temática influenciam o aspecto da distribuição regional destes estudos. Porém, é interessante destacar que, ainda assim, a temática esteve presente em instituições de todas as regiões do país, sendo que o Nordeste e o
Sudeste se destacam no quantitativo de estudos produzidos.

Quadro1: quantidade de estudos por Região

\begin{tabular}{|l|c|}
\hline \multicolumn{2}{|l|}{ Quantidade de estudos por Região } \\
\hline Sudeste & 20 \\
\hline Nordeste & 19 \\
\hline Sul & 4 \\
\hline Norte & 1 \\
\hline Centro Oeste & 1 \\
\hline \multicolumn{2}{|r|}{ total } \\
\hline
\end{tabular}

Fonte: Elaboração própria

De todo modo, mesmo com as discrepâncias na distribuição regional, os estudos apresentam-se presentes em instituições de 11 dos 26 estados da federação, além do Distrito Federal. Destacamos Minas Gerais como o estado com a maior quantidade de estudos produzidos.

Quadro2: quantidade de estudos por estado

\begin{tabular}{|c|c|c|c|c|c|c|c|c|c|c|c|}
\hline \multicolumn{10}{|c|}{ Quantidade de estudos por estado } \\
\hline MG & CE & BA & SC & RJ & PE & RS & SP & RN & ES & AM & DF \\
\hline 10 & 7 & 9 & 2 & 6 & 1 & 2 & 3 & 2 & 1 & 1 & 1 \\
\hline
\end{tabular}

Fonte: Elaboração própria

Foram lidos todos os conjunto com as palavras-chaves, resumos dos 45 estudos, e em julgamos o quanto cada um deles 
se aproximava da temática do SNC, SEC, SMC ou algum de seus elementos relacionados, como conferências ou conselhos.Foram estabelecidos três graus de vinculação da temática: 1- baixo, 2médio, 3- alto. No nível baixo situam-se os trabalhos que possuem relação muito tangencial com a temática de Sistemas de Cultura, trazendo-a como pano de fundo, mas fracamente relacionada com o objeto de estudo tratado pelo autor. O segundo nível, médio, se diferencia do anterior por trazer a temática com algum relevo de importância, mesmo que ela não seja o objeto de estudo ou a temática principal ${ }^{9}$. Por último, os trabalhos classificados com nível alto de relação, são aqueles cujo objeto de estudo envolve diretamente a temática de Sistemas de Cultura, ou algum dos elementos que os compõem, como conselhos e conferências. Ao final da classificação obtivemos 29 trabalhos considerados com nível de relação alto, 6 com nível médio e 10 trabalhos com nível baixo de relação.

Ao observar esses trabalhos também pelo seu âmbito de análise em relação ao ente federado objeto do estudo, chegou-se aos seguintes quantitativos:

\footnotetext{
${ }^{9}$ Por exemplo, um trabalho considerado com baixo nível de relação com a temática tem como objeto de estudo as Bibliotecas Públicas, e embora mencione em algum momento o SNC, não dá relevo à questão. Já aqueles classificados com nível médio de relação têm como objetos de estudo uma política setorial (como dança ou economia criativa) e, embora abordem a política do SNC como contexto de influência na política setorial, ela não é o foco principal do trabalho.
} 
Quadro3: Estudos por nível de relação com a temática e por âmbito de análise

\begin{tabular}{|c|c|c|c|c|c|}
\hline & \multicolumn{3}{|c|}{ nível de relação com a temática } & \multirow{2}{*}{$\begin{array}{c}\text { quantidade por âmbito } \\
\text { de análise }\end{array}$} \\
\hline & & alto & médio & baixo & \\
\hline \multirow{4}{*}{ 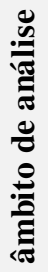 } & União & 8 & 3 & 3 & 14 \\
\hline & Estadual & 3 & 0 & 1 & 4 \\
\hline & Estadual e municipal & 1 & 0 & 0 & 1 \\
\hline & Municipal/municipais & 17 & 3 & 6 & 26 \\
\hline & $\begin{array}{l}\text { quantidade por nível de } \\
\text { relação com a temática }\end{array}$ & 29 & 6 & 10 & 45 \\
\hline
\end{tabular}

Fonte: Elaboração própria

Em relação aos objetos de estudo dos trabalhos que consideramos com nível alto de relação com a temática, obtivemos as seguintes concentrações:

Quadro 4: Elemento principal do objeto de estudo

\begin{tabular}{|c|c|c|c|}
\hline & $\begin{array}{l}\text { Elemento do SNC/SMC em destaque no trabalho } \\
\text { (somente os de nível de relação alto) }\end{array}$ & quantidade & $\begin{array}{c}\text { quantidade } \\
\text { total }\end{array}$ \\
\hline \multirow{3}{*}{ 疍 } & Sistema Nacional de Cultura & 4 & \multirow{3}{*}{8} \\
\hline & $\begin{array}{l}\text { Sistema Nacional de Cultura e Plano Nacional de } \\
\text { Cultura }\end{array}$ & 2 & \\
\hline & Conselho Nacional de Política Cultural & 2 & \\
\hline \multirow{2}{*}{$\frac{\frac{}{8}}{\frac{\pi}{0}}$} & Sistema Estadual de Cultura & 3 & \multirow{2}{*}{4} \\
\hline & Sistema Estadual e Municipal de Cultura & 1 & \\
\hline \multirow{4}{*}{ 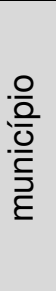 } & Sistema Municipal de Cultura (SMC) & 11 & \multirow{4}{*}{17} \\
\hline & Plano Municipal de Cultura (PMC) & 2 & \\
\hline & Conselho Municipal de Política Cultural (CMPC) & 3 & \\
\hline & Conferência Municipal de Cultura (CMC) & 1 & \\
\hline & total & 29 & 29 \\
\hline
\end{tabular}

Fonte: Elaboração própria 
A partir dos procedimentos de quantificação acima descritos, nosso interesse se voltou para o conteúdo desses estudos. Realizamos duas análises: uma entre aqueles estudos que tratam do âmbito da União e estados; e outra voltada para os estudos que tratam dos municípios. Essa separação foi feita com a intenção de estabelecer comparações entre os estudos, e averiguar se há grandes discrepâncias entre seus resultados. Neste artigo optamos por nos concentrar no âmbito municipal e naqueles estudos que foram por nós considerados com alto nível de relação com a temática.As análises do âmbito da União e estados serão por nós expostas em oportunidade futura.

\section{Análise dos trabalhos de} âmbito municipal

$$
\text { Para uma análise mais }
$$
aprofundada, foram considerados aqueles 18 trabalhos de âmbito municipal com alto grau de relação com a temática, a fim de analisar a consideração dos autores sobre as políticas culturais locais sob a influência do SNC. Ressalvamos que, desse número tivemos que excluir dois estudos que não se encontraram disponíveis na íntegra para download, nem nos sites institucionais de seus Programas de Pós Graduação, nem no Catálogo da CAPES. Portanto, de 16 trabalhos foram lidos: resumos, palavras-chaves, introdução, objetivos/hipóteses e questões de pesquisa; e, conclusão ou consideração final.

Todos os 16 estudos apontaram para algum tipo de avanço nas políticas culturais municipais, seja por maior engajamento da participação, seja por um passo a mais na efetiva organização e valorização das políticas culturais locais. Entretanto, a maioria desses estudos não se esquivou de apontar críticas contundentes às limitações do processo e ao afastamento entre a prática e aquilo que era proposto nas diretrizes da política do MinC.

Destacaremos, primeiramente, alguns dos trabalhos que deram maior relevo às positividades acarretadas pelo processo. Dois autores ressaltam os impactos positivos, sem enumerar 
praticamente nenhum ponto negativo. Ferreira (2017), em seu estudo sobre a participação nas políticas culturais de Oliveira (MG), ressaltou os aspectos da gestão compartilhada, descentralizada e participativa, principalmente com a presença de um conselho deliberativo, consultivo, normativo e paritário. Ao mesmo tempo, Moura (2011), sobre as políticas culturais de Limoeiro do Norte (CE), ressalta visões otimistas do contexto nacional, e seus impactos no município, onde ocorreu a ampliação do conceito de cultura (ainda que de forma tímida e insuficiente), a valorização da cultura local, a maior promoção de projetos culturais, de captação de recursos, e oferta de cursos. O autor destacou a ampliação do horizonte cultural na atuação do órgão gestor.

Já, de modo um pouco mais crítico, Morais (2017), defende que houve inegáveis ganhos, e que 0 estudo de caso do SMC de Três Corações (MG) pode ser um alento em meio ao cenário adverso. Atento às limitações e riscos de seu estudo de caso, o autor menciona descontinuidade da implantação no governo Dilma, e o recuo no governo Temer. Defende que caberia ao ministério um papel mais presente e que a política nacional não deveria ser apenas delegação de poder do centro para periferia.

Outros quatro pesquisadores exaltaram os aspectos positivos nas políticas culturais municipais, embora estes mesmos forneçam com maior detalhamento, críticas ao processo, que na prática se afastaram um pouco das idealizações. Kupski (2012), afirma que o processo no SMC de Rio Grande (RS) foi um período de impulso das políticas culturais municipais, mas os benefícios não atingiram a maioria da população. $A$ autora diz estar ciente que políticas planejadas, na prática, são mediadas pelo campo (no sentido de Bourdieu), e que obviamente não se traduziriam tal e qual planejado. Mas, pelos resultados apresentados em seu estudo de caso, a autora põe em questão a validade do discurso promovido. Em Rio Grande, embora tenha havido um impulso nas políticas culturais, a 
autora defende que não é "aquilo tudo" que se esperava.

Davis (2013) identificou que o PMC e CMPC de Belo Horizonte foram capazes de abrir uma janela para processos políticos em que diferentes atores, conceitos e tecnologias interagem, criando e consolidando novas racionalidades, através de rotinas práticas. $\mathrm{O}$ sistema foi capaz de replicar e reinventar a área da cultura. Para além das estruturas criadas em si, o autor enfatiza a rotina entre elas, observando as novas racionalidades que surgiram a partir destas relações. Porém, o autor faz várias pontuações críticas, ressaltando que nem sempre os ideais estabelecidos são realizados, já que equipe técnica canaliza para si algumas decisões, afastando-se de um processo participativo mais amplo. Curiosamente, identificou que, por mais que os atores envolvidos identifiquem falhas $e$ desafios, têm a percepção de que estão rumo a um Estado compartilhado, planejado, democrático e contraditoriamente "técnico" e "apolítico". Os fracassos são por eles relacionados a desvios pontuais, como falta de tempo ou frustrações participativas, sem nunca desacreditarem no processo como um todo.

A implantação do SMC em Abaetetuba (PA) representa para Silva (2015) um avanço para o município por proporcionar um debate entre os diversos setores que simpatizam ou militam nessa área, embora ainda não tenha surtido em políticas concretas. Para o autor, modificar a mentalidade de pessoas que cresceram cercadas por um modelo tradicional de gestão, com práticas clientelistas e assistencialistas, onde a cultura é observada como política secundária, é um processo difícil. Mesmo assim, ainda que pouco perceptíveis, alguns avanços ocorreram e o mais importante foi despertar nas pessoas o interesse pelo direito à cidadania cultural. E frisou a necessidade de superar os entraves políticos, administrativos e ideológicos; um esforço que vai além da gestão municipal, e deveria envolver a participação federal e estadual que ainda resistem em atuar de forma sistêmica. 
Vitória (2015) ressalta que 0 SMC de Viçosa (MG), mesmo com fragilidades, provocou maior envolvimento, principalmente dos trabalhadores do meio cultural, fazendo com que eles se mobilizassem e se organizassem. Os agentes culturais de Viçosa, seja acatando normas legais ou copiando o que tem sido feito por outras localidades, vêm buscando se adaptar ao novo cenário do campo da cultura no Brasil. E, mesmo que ainda esteja em fase transitória, observou que a nova cena vem trazendo esperança de mudança aos envolvidos. Por outro lado, 0 autor identifica que as entidades do SMC ainda estão muito dependentes do "órgão gestor", sendo afetados ou paralisados quando este apresenta qualquer tipo de problema. Por isso, sua crítica se volta ao caráter de Estado provedor, do tipo paternalista e centralizador, o que diverge do objetivo do SNC.

As críticas mencionadas até o momento apresentaram-se como contrapontos aos principais avanços acarretados pela política identificados pelos pesquisadores. quadro a seguir sintetiza esse balanço em cada uma das 16 pesquisas.

Quadro 5: Síntese dos avanços e críticas nos estudos investigados

\begin{tabular}{|l|l|l|l|}
\hline Autores & $\begin{array}{l}\text { Objeto de } \\
\text { estudo }\end{array}$ & $\begin{array}{l}\text { Principal avanço alcançado } \\
\text { com a política }\end{array}$ & Principais críticas ao processo \\
\hline $\begin{array}{l}\text { Semensat } \\
\text { o (2010) }\end{array}$ & $\begin{array}{l}\text { CMC de } \\
\text { Campos (RJ) }\end{array}$ & $\begin{array}{l}\text { Avanços na descentralização e } \\
\text { articulação de políticas culturais }\end{array}$ & $\begin{array}{l}\text { Tradições políticas resistem aos } \\
\text { princípios democráticos e } \\
\text { processo é descontinuado. } \\
\text { Descentralização só acarretaria } \\
\text { políticas efetivas com empenho } \\
\text { municipal. }\end{array}$ \\
\hline $\begin{array}{l}\text { Moura } \\
(2011)\end{array}$ & $\begin{array}{l}\text { Impactos do } \\
\text { SNC e PNC } \\
\text { em Limoeiro } \\
\text { do Norte CE }\end{array}$ & $\begin{array}{l}\text { Ampliação das políticas culturais } \\
\text { e do conceito de cultura, } \\
\text { valorização da cultural local. }\end{array}$ & $\begin{array}{l}\text { Críticas brandas: ampliação das } \\
\text { ações e do conceito de cultura } \\
\text { ainda é tímido e insuficiente. }\end{array}$ \\
\hline $\begin{array}{l}\text { Kupski } \\
(2012)\end{array}$ & $\begin{array}{l}\text { Impactos do } \\
\text { SNC em Rio } \\
\text { Grande (RS) }\end{array}$ & $\begin{array}{l}\text { Impulso das políticas culturais } \\
\text { municipais }\end{array}$ & $\begin{array}{l}\text { Política aquém da expectativa e } \\
\text { não alcança maioria da } \\
\text { população. }\end{array}$ \\
\hline $\begin{array}{l}\text { Bastos } \\
(2013)\end{array}$ & $\begin{array}{l}\text { SMCs do } \\
\text { Vale do } \\
\text { Jiquiriçá, } \\
\text { Bahia. }\end{array}$ & $\begin{array}{l}\text { Gestão participativa atingiu } \\
\text { patamar significativo }\end{array}$ & $\begin{array}{l}\text { Dificuldade e/ou resistência da } \\
\text { parte de alguns municípios na } \\
\text { criação das estruturas do SMC }\end{array}$ \\
\hline
\end{tabular}




\begin{tabular}{|c|c|c|c|}
\hline Davis & $\begin{array}{l}\text { PMC e } \\
\text { CMPC de } \\
\text { Belo } \\
\text { Horizonte } \\
\text { (MG) } \\
\end{array}$ & $\begin{array}{l}\text { Elaboração do PMC viabilizou } \\
\text { abertura para novos atores, } \\
\text { conceitos e tecnologias, criando } \\
\text { e consolidando novas } \\
\text { racionalidades. }\end{array}$ & $\begin{array}{l}\text { Tempo da administração é } \\
\text { diferente do da participação. } \\
\text { Canalização de decisões na } \\
\text { esfera técnica, e não na ampla } \\
\text { participação }\end{array}$ \\
\hline $\begin{array}{l}\text { Melo } \\
(2013)\end{array}$ & $\begin{array}{l}\text { CMPC de } \\
\text { Fortaleza } \\
\text { (CE) }\end{array}$ & $\begin{array}{l}\text { Conselho confere maior } \\
\text { transparência às decisões do } \\
\text { poder público,caminhando para } \\
\text { a efetiva formulação das } \\
\text { políticas públicas de cultura }\end{array}$ & $\begin{array}{l}\text { Espaços democráticos não } \\
\text { significam democratização da } \\
\text { gestão municipal, pois outras } \\
\text { áreas não se democratizam. } \\
\text { CMPC tem baixo grau de } \\
\text { institucionalidade. }\end{array}$ \\
\hline $\begin{array}{l}\text { Boel } \\
(2014)\end{array}$ & $\begin{array}{l}\text { SMCs de } 14 \\
\text { municípios } \\
\text { de Santa } \\
\text { Catarina }\end{array}$ & $\begin{array}{l}\text { SNC é caminho que aponta } \\
\text { paradescentralizaçãoadministrat } \\
\text { iva, participação social, redução } \\
\text { das desigualdades }\end{array}$ & $\begin{array}{l}\text { Dificuldade dos municípios para } \\
\text { implantar o SMC. Ausência de } \\
\text { estruturas de políticas culturais e } \\
\text { de cultura da participação, } \\
\text { conflitos partidários. }\end{array}$ \\
\hline $\begin{array}{l}\text { Silva } \\
(2015)\end{array}$ & $\begin{array}{l}\text { SMC de } \\
\text { Abaetetuba } \\
\text { (PA) }\end{array}$ & $\begin{array}{l}\text { Viabilização do debate entre } \\
\text { diversos setores que } \\
\text { simpatizam e militam na cultura; } \\
\text { estímulo pelo direito à cidadania } \\
\text { cultural. }\end{array}$ & $\begin{array}{l}\text { Resistência do governo ao } \\
\text { modelo democrático e ao conceito } \\
\text { amplo de cultura; interesse em se } \\
\text { enquadrar apenas pelos repasses } \\
\text { de fundo }\end{array}$ \\
\hline $\begin{array}{l}\text { Vitória } \\
(2015)\end{array}$ & $\begin{array}{l}\text { SMC de } \\
\text { Viçosa (MG) }\end{array}$ & $\begin{array}{l}\text { Estímulo à participação social, } \\
\text { com mobilização e organização } \\
\text { dos trabalhadoresculturais }\end{array}$ & $\begin{array}{l}\text { Centralização do SMC no órgão } \\
\text { gestor: demais estruturas } \\
\text { dependentes, sem autonomia e } \\
\text { paralisadas quando a gestão } \\
\text { enfrenta algum problema }\end{array}$ \\
\hline $\begin{array}{l}\text { Gonçalve } \\
\text { s (2016) }\end{array}$ & $\begin{array}{l}\text { CMPCs da } \\
\text { Baixada } \\
\text { Fluminense }\end{array}$ & $\begin{array}{l}\text { Conselhos são marco na } \\
\text { democratização das políticas } \\
\text { culturais }\end{array}$ & $\begin{array}{l}\text { Falta articulação entre CMPC e } \\
\text { poder público; pouca influência da } \\
\text { sociedade nas decisões. } \\
\text { Participação limitada pelas } \\
\text { relações de poder entre órgão } \\
\text { gestor e CMPC. }\end{array}$ \\
\hline $\begin{array}{l}\text { Ferreira } \\
(2017)\end{array}$ & $\begin{array}{l}\text { CMPC e } \\
\text { Conferência } \\
\text { no SMC de } \\
\text { Oliveira } \\
\text { (MG) } \\
\end{array}$ & $\begin{array}{l}\text { Políticas culturais mais } \\
\text { descentralizadas e } \\
\text { participativas; gestão } \\
\text { compartilhada. }\end{array}$ & não há críticas contundentes \\
\hline $\begin{array}{l}\text { Souza } \\
(2016)\end{array}$ & $\begin{array}{l}\text { SMC e } \\
\text { CMPC de } \\
\text { Petrópolis } \\
(\mathrm{RJ})\end{array}$ & $\begin{array}{l}\text { Aumento (limitado) da } \\
\text { democracia participativa }\end{array}$ & $\begin{array}{l}\text { CMPC não promove } \\
\text { demodiversidade, restringindo-se } \\
\text { à intervenção branda da } \\
\text { sociedade na tomada de decisão, } \\
\text { ainda dominada pelo poder } \\
\text { público }\end{array}$ \\
\hline $\begin{array}{l}\text { Aquino } \\
\text { (2017) }\end{array}$ & \begin{tabular}{l|} 
SMCs de \\
Betim, \\
Contagem e \\
Sabará (MG)
\end{tabular} & $\begin{array}{l}\text { Experiências de participação e } \\
\text { desenvolvimento de políticas } \\
\text { culturais compatíveis com o } \\
\text { contexto local }\end{array}$ & $\begin{array}{l}\text { Efetividade dos SMCs } \\
\text { comprometidas por } \\
\text { descontinuidades (do gestor e } \\
\text { prefeito). Governos consideram } \\
\text { conselhos como ameaça ou mero } \\
\text { requisito de formalidades. }\end{array}$ \\
\hline $\begin{array}{l}\text { Morais } \\
(2017)\end{array}$ & $\begin{array}{l}\text { SMC de Três } \\
\text { Corações } \\
\text { (MG) }\end{array}$ & $\begin{array}{l}\text { Ganhos inegáveis nas políticas } \\
\text { culturais municipais, mesmo } \\
\text { com limitações e riscos. }\end{array}$ & $\begin{array}{l}\text { Descontinuidades do SNC e fraca } \\
\text { coordenação do MinC. } \\
\text { Autopromoção de atores locais }\end{array}$ \\
\hline
\end{tabular}




\begin{tabular}{|c|c|c|c|}
\hline $\begin{array}{l}\text { Paschoali } \\
\text { k (2017) }\end{array}$ & $\begin{array}{l}\text { Impactos do } \\
\text { SNC em } \\
\text { Ribeirão } \\
\text { Preto (SP) }\end{array}$ & $\begin{array}{l}\text { Adesão ao SNC estimulou o } \\
\text { movimento cultural na cidade, } \\
\text { dando sustentação à estrutura } \\
\text { de participação. }\end{array}$ & $\begin{array}{l}\text { Conflitos da participação } \\
\text { acirraram-se, produzindo recuo da } \\
\text { sociedade nos espaços } \\
\text { institucionalizados. A aprovação } \\
\text { da lei não garantiu políticas mais } \\
\text { efetivas, pois os processos } \\
\text { políticos ainda estão submetidos a } \\
\text { hierarquia do poder }\end{array}$ \\
\hline $\begin{array}{l}\text { Melo } \\
(2018)\end{array}$ & $\begin{array}{l}\text { CMPC de } \\
\text { Fortaleza } \\
\text { (CE) e Belo } \\
\text { Horizonte } \\
\text { (MG) }\end{array}$ & $\begin{array}{l}\text { Conselhos auxiliam na } \\
\text { construção democrática e } \\
\text { transparente das políticas } \\
\text { culturais }\end{array}$ & $\begin{array}{l}\text { Efetividade comprometida por } \\
\text { fatores internos e externos aos } \\
\text { CMPCs: descontinuidades, } \\
\text { problemas na gestão, disputas } \\
\text { pessoais (internas e partidárias); } \\
\text { falta de representatividade. } \\
\text { Resistência do Estado em } \\
\text { partilhar o poder }\end{array}$ \\
\hline
\end{tabular}

Fonte: Elaboração própria

Além do saldo exposto acima, mencionaremos a seguir outras críticas que se apresentam de forma recorrente nos trabalhos. A intenção é pontuar como e quanto esses comportamentos políticos são frequentes, mesmo em contextos e enfoques diferentes.

$$
\text { Silva (2015), sobre }
$$
Abaetetuba (PA), identificou que a simples formalidade da adesão não garante o desenvolvimento de uma política participativa, coletiva, com gestão social. Críticas similares, a respeito de como a adesão formal ou a própria criação (mesmo que em lei) de estruturas ligadas ao SMC não garante seu pleno funcionamento aparecem na maioria dos trabalhos. Boel (2014), por exemplo, sobre SMCs do estado de
Santa Catarina, identificou que apesar da maioria dos gestores compreenderem conceitos propostos e a relação da cultura com política e desenvolvimento, os processos ainda estão distantes do modelo proposto pelo SNC. Igualmente, afirma que somente a construção dos organismos propostos não garante êxito das políticas culturais. Melo (2013) a respeito do CMPC de Fortaleza (CE), averiguou em sua pesquisa 0 esforço do poder executivo para ampliar canais de participação, mas, para a autora, somente a abertura desses espaços não significa efetiva democratização, visto que outras áreas de gestão não se democratizam. Paschoalik (2017), em sua pesquisa sobre Ribeirão 
Preto (SP), narrou a constituição de todos os elementos de um SMC,após um longo processo. Paradoxalmente, o município nunca teve um orçamento tão baixo, programas culturais quase que inexistentes e a predominância de políticas de eventos. Apesar do processo participativo e do SMC em funcionamento, as instâncias de participação estão esvaziadas e desacreditadas. Semensato (2010), sobre a CMC de Campos (RJ), descreveu que 0 evento foi realizado conforme as orientações do MinC. Porém, após sua realização não houve zelo com as resoluções; ou sequer resquícios de que ela foi realizada, nem mesmo através da documentação, que é inacessível através de consulta pública, o que é um descaso do poder público para com o processo participativo. Vitória (2015), a partir do estudo do SMC de Viçosa (MG), diz que há um despreparo por parte dos municípios em atender todas as exigências do SNC, e que as imposições para fazer parte do sistema nacional têm levado à criação de estruturas ainda frágeis no nível municipal. Acredita que uma das grandes dificuldades na implantação do SMC decorre do fato das pessoas terem dificuldade de pensar e trabalhar de forma sistêmica, ou seja, as estruturas interagindo sob uma orientação comum. O que o autor vê, na prática, são sistemas implantados, ou em fase de implementação, operando de forma não sistematizada. Bastos (2013) relata que alguns gestores municipais de Santa Catarina, embora tenham compreendido a proposta da gestão compartilhada, têm dificuldade na sua implementação.

As disfunções das estruturas planejadas para os SMC também estão nas esferas da participação. Os conselhos, ainda que formulados, implantados e em funcionamento, se afastam em maior ou menor medida daquilo que era previsto, em três trabalhos. Melo (2013), sobre o CMPC de Fortaleza, afirma que o órgão possui regular capacidade propositiva, discreto poder de influência sobre 0 processo de definição das políticas culturais, e em sua visão, possui baixo grau de institucionalidade. Em 2018 a mesma pesquisadora, sobre 
os CMPCs de Belo Horizonte e Fortaleza diz que as decisões destes órgãos afetam apenas parcialmente as decisões, pois muitas das deliberações não ocorrem. Classifica que sua capacidade propositiva é regular, e seu poder de influência nas decisões políticas é relativo (MELO, 2018). Nesse mesmo sentido, Souza (2016) identifica que no Conselho de Petrópolis (RJ), apesar de a lei garantir poder de decisão, o órgão tem uma capacidade restrita de interferência deliberativa no rumo da gestão pública. Para ela, o órgão não gera turbulência na dinâmica política-institucional hegemônica, que continua assegurando 0 domínio do poder de decisão nas mãos do poder público.

$$
\text { É interessante ressaltar que }
$$
três pesquisadores associam as falhas da implantação e 0 afastamento das diretrizes alógicas políticas conservadoras e tradicionalistas enraizadas na cultura política daqueles municípios. É o que se apresenta nas opiniões de Paschoalik (2017) sobre Ribeirão Preto (SP), quando diz que apesar dos recentes esforços para democratização, os processos políticos ainda estão fortemente submetidos a uma cultura hierárquica do poder institucional; Silva (2015), quando afirma que o conceito tridimensional de cultura ainda não foi assimilado pelo governo de Abaetetuba, onde vigoram tradições políticas conservadoras, e por isso o poder público resiste ao modelo, ao mesmo tempo em que tenta se enquadrar nele, gerando um dilema da administração municipal, interessada nos repasses; e Semensato (2010), sobre a conferência de Campos (RJ), para quem as instituições locais e os comportamentos arraigados na cultura política da sociedade limitaram os princípios democráticos.

O sintoma das tradições políticas elitistas também é relatado no interior das estruturas dos conselhos, em quatro das pesquisas. É o caso de Aquino (2017), sobre SMCs de Minas Gerais, ao relatar que grupos de interesse que já eram dominantes se aproveitam das estruturas para manter seu status quo. E Gonçalves 
(2016), sobre os CMPCs da Baixada Fluminense, defende que a institucionalização de espaços de participação social é importante para a democratização, mas chama atenção que eles podem reforçar práticas autoritárias do Estado. Kupski (2012) identificou, em Rio Grande (RS), manutenção das posições no campo, onde atores que já se destacavam foram os que mais se impulsionaram, e os demais adotaram estratégias de aproximação com dominantes. Semensato (2010) identificou que o conselho do município de Campos (RJ) não demonstrava interesse nas disposições elencadas pela conferência. A autora defendeu que cabe aos governos municipais empreender esforços para conseguir que o caráter democrático se estabeleça; do contrário, uma velha estrutura, autoritária e oligárquica, perdurará, mesmo que numa aparência nova legitimada por argumentos democráticos.

É válido ressaltar que 8 estudos enfatizaram os conflitos gerados na relação entre Conselho e órgão gestor, sendo 4 os autores que focam um grau bastante alto de embates, e outros 4 apontam limitações da participação.Essas estruturas de participação são vistas como ameaça pelo órgão gestor, e parte da administração pública não o entendia, nem entendia 0 Sistema, como relatou Aquino (2017). Por isso, ocorre a resistência e até a recusa do Estado em partilhar poder, relata Melo (2018), que defende que o órgão gestor precisa exercer escuta mais atenta ao órgão participativo e usufruir dessa relação para se desconstruir. Os conflitos também foram bastante pontuados por Paschoalik (2017)em Ribeirão Preto, onde o aumento da participação dos atores sociais no planejamento e gestão dificultou diálogos entre sociedade civil e poder público, ao ponto de produzir ao longo do tempo um recuo significativo da participação nos espaços institucionalizados. Gonçalves (2016), sobre os conselhos da Baixada Fluminense, relatou a falta de articulação entre essas instâncias e o poder público, que muitas vezes não entende a função democrática do órgão e 0 utiliza em benefício próprio. Com 
isso, a instituição participativa acaba sendo pouco influente nas decisões públicas, além de que, seu poder é concentrado em poucos conselheiros ligados ao poder público.

Nos outros 4 autores, verificamos a participação no órgão, mas de modo limitado pelo poder público. Davis (2013) descreve o ambiente em Belo Horizonte (MG) com efeitos de agência e autonomia parcial. Semensato (2010) relatou que o CMPC de Campos (RJ), resultante do processo da conferência, tem suas ações limitadas já que o município não disponibiliza um orçamento para ele. Souza (2016) diz que o conselho em Petrópolis (RJ) não é capaz de gerar demodiversidade, isto é, a complementaridade entre a democracia representativa e a democracia participativa. No máximo há "diálogo" e a "escuta", fazendo com que a possibilidade de intervenção da sociedade civil nos processos de tomada de decisão fosse considerada de maneira branda. Para a autora, embora a experiência seja um exercício de democracia participativa, ela vem se comportando

como

um

"penduricalho da democracia representativa", já que continua sendo assegurado o domínio do poder de decisão nas mãos do poder público. Melo (2013) também ressaltou 0 discreto poder de influência do Conselho de Fortaleza nas definições das políticas culturais do município.

Outros pontos interessantes merecem ser aqui ressaltados a respeito das instituições de participação. Melo (2018) identificou que a presidência do conselho é essencial para a legitimidade, o bom andamento dos processos e a efetividade das deliberações. Entretanto, duas críticas foram relatadas a esse respeito: Souza (2016) defende a extinção da função do presidente, que, em sua opinião, concentra muito poder, sobretudo quando o presidente é do poder executivo; e, os entrevistados de Gonçalves (2016) apontaram que a figura em geral é o secretário de cultura, pontuando isso como um problema.

Ainda sobre o funcionamento dos CMPCs, duas autoras, Gonçalves (2016) e Melo (2018), 
criticaram o fato de que o conselho se volta demasiadamente para questões internas, como a burocratização de seu funcionamento, regimentos, grupos temáticos etc. Essa organização interna do conselho demanda muito dos conselheiros, tomando 0 espaço que deveria ser de debate sobre as políticas culturais. Por outro lado, Melo (2018) também pondera, frisando a importância da institucionalidade, ao identificar que a inexistência ou indefinição do modus operandi prejudica a efetividade das discussões.A mesma autora ainda aponta rumos para melhor efetividade dessas instâncias participativas: valorizar o SNC, valorizar a diversidade e garantir representatividade dentro do órgão cultural; fortalecer a estrutura técnico administrativa dos conselhos, estabelecer metas e objetivos, capacitação de conselheiros e a extensão do mandato do conselheiro na nova gestão.

Tal como Melo (2018), Souza (2016) faz recomendações para melhor efetividade dessas instâncias de participação, que em muito se aproximam deste primeiro estudo, a exemplo de: proposição de regras eleitorais condizentes com a representatividade, valorização das diferenças dentro do órgão, cautela para não se reproduza a lógica da democracia representativa, existência de programas de formação e capacitação para conselheiros. Além desses, a autora prega também a ampliação das competências do órgão rumo a compartilhamento equiparado de poder de decisão entre conselho e órgão gestor, a promoção de articulação e alteridade entre os membros, a existência do Sistema de Informações e Indicadores Culturais para subsidiar decisões, a utilização do PMC como orientador das ações e decisões e a operacionalização publicizada de um fundo de cultura.

É interessante verificar que três pesquisadores mencionaram a falta de tempo da política para que ela se torne mais efetiva. Bastos (2013) sobre os municípios do Vale de Jiquiriçá (BA) mencionou que alguns até estão em estágios mais avançados, mas muitos ainda não 
tiveram tempo hábil para a implementação. Aquino (2017) foi outro a mencionar que o prazo de dois anos para execução do plano de trabalho sugerido pelo MinC não é exequível. Por último, os entrevistados de Davis (2013) sobre o PMC de Belo Horizonte atribuem à falta de tempo a deficiência do êxito da política.

Mais três pesquisadores, Aquino (2017), Bastos (2013) e Gonçalves (2016), mencionam, ainda que de forma breve, a falta de recursos, ressaltando necessidade da viabilização do repasse de fundo do governo federal para efetivação da política em âmbito local.

Os sintomas políticos análogos identificados nos diferentes trabalhos, e acima abordados, foram sintetizados no quadro6, destacando-se nas células pintadas os temas que mais se repetem. Ressalta-se que as categorias não foram criadas previamente, e sim, a partir da leitura e identificação das semelhanças entre os trabalhos.

\section{Quadro 6: Críticas recorrentes nos trabalhos}

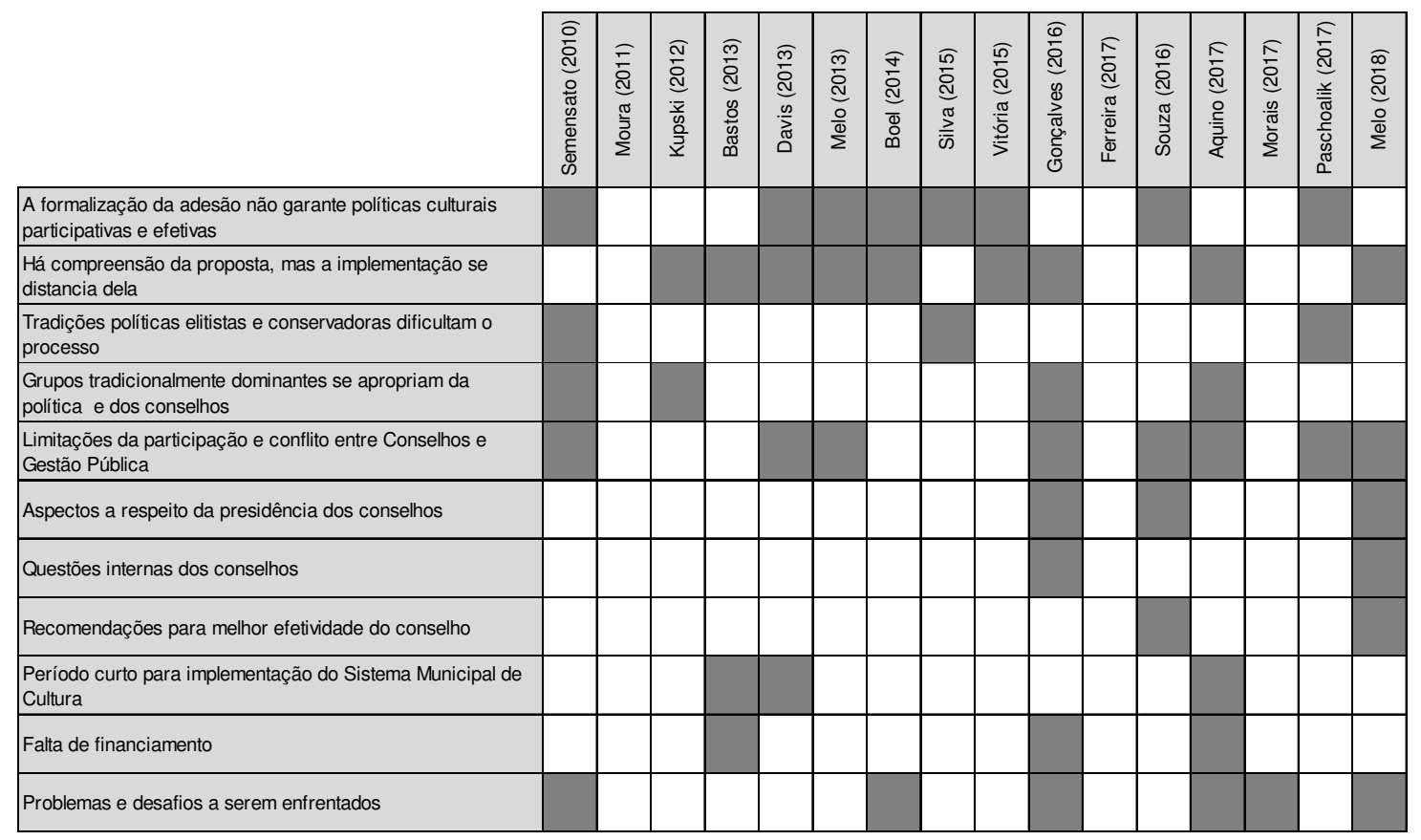

Fonte: Elaboração própria 
Apesar de todos os trabalhos mencionarem o modelo de gestão do SMC como algo positivo, aqueles assinalados na última linha apontam desafios enfrentados no momento da implementação da política, e que não foram superados. Alguns deles são bastante semelhantes aos problemas que a literatura sobre políticas culturais identifica tradicionalmente no país, os quais,inclusive,o SNC apresentouse como política pública para superá-los. Boel (2014) enumera falta de vontade política, individualismo, falta de cultura da participação, desinformação, disputas político-partidárias. Aquino (2017) frisa a baixa capacidade institucional dos municípios, rigidez orçamentária, rotatividade de partidos, instabilidades políticas e descontinuidades e falta de repasse de fundo. Gonçalves (2016) também cita a faltade recursos, a dificuldades técnicas e ausência qualificação para implementação. Melo (2018) também menciona as descontinuidades das gestões participativas nos conselhos, seus problemas de gestão, as disputas internas pessoais e partidárias, falta de representatividade. De modo bastante parecido, Semensato (2010) critica a ausência de políticas culturais planejadas e continuadas, frisa o despreparo dos gestores, a existência de práticas personalistas e assistencialistas, descontinuidades, e a inexistência de registros oficiais sobre a execução da política e dos processos participativos. Morais (2017) critica a desarticulação da cultura com outros setores de políticas públicas dos municípios.

Diante de todos esses aspectos dos estudos, constatamos que a grande maioria dos autores estão antenados para as críticas e limitações dos processos, embora destaquem também os avanços políticos ligados à implementação dos sistemas de cultura e/ou suas instâncias de participação. Nesse sentido, outros três pontos merecem destaque, apesar de terem sido mencionados de forma isolada por alguns autores: as consultorias da UFBA $^{10}$ ofertada aos municípios foi

\footnotetext{
${ }^{10}$ Trata-se do Projeto de Apoio e Assistência Técnica à Elaboração de Planos Municipais de Cultura firmado por um convênio entre Ministério da Cultura e Universidade Federal da Bahia, a partir da
} 
destacada por Davis (2012) por serem consideradas um "braço técnico", carregado de conhecimento racional, e científico, isento das lógicas políticas locais. Bastos (2013) observou que a implementação dos Sistemas Municipais e os processos participativos, provocaram a inclusão das demandas culturais nas plataformas políticas dos candidatos às novas eleições. Aquino (2017), por sua vez, deu destaque à pressão popular no processo de implementação. Reconhece que as experiências de participação foram limitadas, mas de todo modo, foi um avanço, e que de fato as políticas culturais nos municípios que estudou desenvolveram-se. $\mathrm{O}$ autor defende a necessidade de reformular a política, mas dando continuidade aos modelos de valorização da participação.

demanda do Fórum Nacional de Dirigentes de Cultura de Capitais e de Cidades de Regiões Metropolitanas. O projeto visava fornecer apoio técnico para estruturação de Sistemas Municipais de Cultura. Foram três edições, ocorridas entre 2012 e 2018 (https://planosmunicipaisdecultura.ufba.br/). Davis (2012) refere-se à edição de 2012, que atendeu os municípios que fizeram parte de sua pesquisa.

\section{Conclusão}

No esforço deste estudo foi identificado, como previsível, um aumento da quantidade de estudos relacionados ao SNC ao longo dos anos, e, como é próprio das Políticas Culturais,

a multidisciplinaridade. Observamos também a distribuição regional, que,embora tenhamos ciência de que essa distribuição se refere às instituições de pós-graduação vinculadas, consideramos ser um indicativo de que a política foi disseminada amplamente pelo país, e reconhecida como objeto de estudo acadêmico.

Em geral os estudos dão ênfase à valorização da cultura, entendida em seu sentido ampliado, da diversidade cultural e nos processos participativos. A participação social e o federalismo são as linhas teóricas recorrentes para se falar do SNC e SMCs. Ressaltamos a grande quantidade de estudos que focam o âmbito municipal, e nestes, todos defenderam 0 modelo de gestão apontando impactos positivos relacionados à valorização da cultura como política pública. Por 
outro lado, praticamente todos reconhecem as falhas e dificuldades de implantação e das limitações da política; como os problemas técnicos e de financiamento, os entraves à participação e a preponderância de uma lógica política conservadora. São olhares bastante similares em todos os 16 estudos que foram alvo de leitura mais aprofundada para este presente artigo.

Portanto, nossa questão inicial foi respondida. Os trabalhos ainda que sob áreas de conhecimento diversas, com objetivos e métodos particulares, e produzidos em contextos diferentes, dialogam. Os pesquisadores apresentam resultados análogos e ponderações parecidas sobre a política. Alguns aspectos são relatados com algumas diferenças, ainda sim compatíveis e raramente contraditórios. Os achados recorrentes, seja em relação aos impactos considerados positivos, mas principalmente sobre as dificuldades de implementação e frustração da política, devem ser observados a fim de aguçar os olhares de pesquisadores que vão empreender na temática; ou ainda para repensar de modo crítico a própria política.

\section{Referências bibliográficas:}

AQUINO, Rafael Luiz de. As políticas de cultura nos municípios da região metropolitana de Belo Horizonte: Entre os governos Estadual e Federal. (Mestrado em Ciências Sociais). Pontifícia Universidade Católica de Minas Gerais, Belo Horizonte, 2017.

BARBALHO, Alexandre. Sistema Nacional de Cultura: campo, saber e poder. Fortaleza: edUECE, 2019.

BASTOS, Ana Rita de Jesus. A organização dos Sistemas Municipais de Cultura no Território do Vale do Jiquiriçá - 2007 a 2010. (Mestrado em Cultura e Sociedade). Universidade Federal da Bahia, Salvador, 2013.

BOELL, Adilson. Relações Teóricas e Práticas entre o Sistema Nacional De Cultura e o Programa Territórios da Cidadania do Planalto Norte Catarinense. (Mestrado em Desenvolvimento Regional). Universidade do Contestado, Canoinhas, 2014.

BRASIL. Constituição Federal de 1988. Emenda Constitucional no71 de 29 de Novembro de 2012. Disponível em: http://www.planalto.gov.br/ccivil_03/ constituicao/constituicao.htm Acesso: 10 mar. 2020.

DAVIS, Pedro Gondim. O CPF da cultura - conselho, plano e fundo como instrumentos de governo no processo de institucionalização da 
SEMENSATO, Clarissa Alexandra G.; BARBALHO, Alexandre Almeida. Sistema Nacional de Cultura: um estado da arte da produção acadêmica com foco nos estudos de caso de municípios.PragMATIZES - Revista Latino-Americana de Estudos em Cultura, Niterói/RJ, Ano 10, n. 19, p. 350-379, set. 2020.

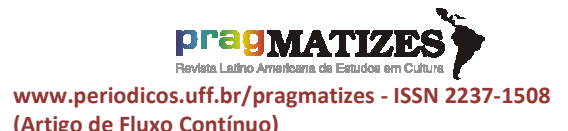

(Artigo de Fluxo Contínuo) "cultura". Reflexões a partir do caso de Belo Horizonte. (Mestrado em Antropologia Social). Universidade Federal do Rio de Janeiro, Rio de Janeiro, 2013.

FERREIRA, Norma Sandra de Almeida. $s$ pesquisas denominadas "estado da arte". Educação \& Sociedade, vol.23, n.79, p.257-272, 2002.

FERREIRA, Thais Caroline. $A$ Participação Social na estruturação da Política Cultural em Oliveira (MG): Uma análise à luz da Sociologia Pragmática. (Mestrado Profissional em Administração Pública). Universidade Federal de Lavras, Lavras, 2017.

GONCALVES, Marina Teixeira. $A$ participação social nos Conselhos Municipais de Cultura da Baixada Fluminense. (Mestrado em Administração). Universidade Federal Rural do Rio de Janeiro, Seropédica, 2016.

KUPSKI, Larisse. A Dinâmica do Campo das Políticas Culturais no Município do Rio Grande. (Mestrado em Administração). Universidade Federal do Rio Grande do Sul, Porto Alegre, 2012.

MELO, Renata Nunes Pereira. A cultura da participação $e$ a participação na Cultura: análise da efetividade da participação social nos Conselhos Municipais de Política Cultural de Fortaleza e Belo Horizonte. (Doutorado em Cultura e Sociedade). Universidade Federal da Bahia, Salvador, 2018.

MELO, Renata Nunes Pereira. Conselho Municipal de Política Cultural - CMPC - do município de Fortaleza: trajetórias participativas?(Mestrado
Sociologia). Universidade Estadual do Ceará, Fortaleza, 2013.

MINC (Ministério da Cultura). Estruturação, Institucionalização e Implementação do SNC. MINC:CNPC:SAI. Dezembro, 2011

MORAIS, Paulo de. Ninguém me reconhece como grande cidadão: desafios da participação em Três Corações. (Mestrado em Gestão Pública e Sociedade). Universidade Federal de Alfenas, Varginha, 2017.

MOURA, José Gledson Nogueira. Políticas culturais e gestão cultural: a Secretaria Municipal da Cultura e do Turismo - SEMUC (2005-2010) de Limoeiro do Norte-CE. (Mestrado em Ciências Sociais). Universidade Federal do Rio Grande do Norte, Natal, 2011.

PASCHOALICK, Jonas Pereira. $O$ Sistema Nacional De Cultura: aspectos contraditórios entre institucionalização e participação no setor cultural de Ribeirão Preto. (Mestrado em Ciências Sociais). Universidade Estadual Paulista Júlio de Mesquita Filho, Araraquara, 2017.

PEIXE, João Roberto. A importância estratégica do Sistema Nacional de Cultura. In: MINC (Ministério da Cultura). Estruturação, Institucionalização e Implementação do SNC. MINC:CNPC:SAI. Dezembro, 2011.

PT - PARTIDO DOS TRABALHADORES. A Imaginação a Serviço do Brasil. Caderno de Campanha. São Paulo: Fundação Perseu Abramo, 2002.

RUBIM, Antônio Albino Canelas. Políticas Culturais entre o possível e o impossível. O público e o privado. 
Revista do PPG em Sociologia da Universidade Estadual do Ceará, n. 9, Janeiro/Junho, 2007.

RUBIM, Antônio Albino Canelas; BARBALHO, Alexandre; CALABRE, Lia. (orgs). Políticas culturais no governo Dilma. Salvador: EDUFBA, 2015.

SANTOS, Marcelo Augusto de Paiva dos. Políticas culturais, um campo em formação: explorações a partir de metodologias informacionais e cientométricas. (Mestrado em Sociologia e Antropologia). Universidade Federal do Rio de Janeiro, Rio de Janeiro, 2017.

SEMENSATO, Clarissa Alexandra Guarjardo. As Conferências Municipais de Cultura como estratégia de descentralização e participação para as Políticas Culturais no Brasil: o caso de Campos dos Goytacazes/RJ, 2006. (Mestrado em Políticas Sociais). Universidade Estadual do Norte Fluminense Darcy Ribeiro, Campos dos Goytacazes, 2010.

SILVA, Edilson Moura da. $O$ Sistema Nacional de Cultura e a gestão da política cultural em nível municipal: o caso de Abaetetuba. (Mestrado em Administração). Universidade da Amazônia, Belém, 2015.

SOARES, Magda Becker; MACIEL, Francisca. A construção do conhecimento. In.: SOARES, Magda Becker; MACIEL, Francisca (orgs). Alfabetização. Brasília: MEC/Inep/Comped, 2000.

SOUZA, Ana Clarissa Fernandes de.Democracia e compartilhamento da gestão pública de cultura: problematizando a participação social institucionalizada no Sistema Municipal de Cultura de Petrópolis RJ. (Mestrado em Cultura e Territorialidades). Universidade Federal Fluminense, Niterói, 2016.

VICENTE, Tânia Aparecida de Souza. O Centro de Referência em Políticas Culturais e Gestão. In: CALABRE, Lia; DOMINGUES, Alexandre (orgs). Estudos sobre políticas culturais e gestão da cultura: análises do campo da produção acadêmica e de práticas de gestão. Rio de Janeiro: Fundação Casa de Rui Barbosa, 2019.

VITORIA, Jose Ricardo. Análise institucional do Sistema Municipal de Cultura no contexto brasileiro. (Mestrado em Administração). Universidade Federal de Viçosa, Viçosa, 2015. 